\title{
SOCIEDADE E EDUCAÇÃO EM ROUSSEAU: DO PENSAMENTO POLÍTICO AO PROJETO DE EDUCAÇÃO NATURAL E MORAL
}

\author{
SOCIEDAD Y EDUCACIÓN EN ROUSSEAU: DEL PENSAMIENTO POLÍTICO \\ AL PROYECTO DE EDUCACIÓN NATURAL Y MORAL
}

SOCIETY AND EDUCATION IN ROUSSEAU: FROM THE POLITICAL THOUGHT TO THE PROJECT OF NATURAL AND MORAL EDUCATION

\author{
Sophia Calil BREYMAIER ${ }^{1}$
}

RESUMO: Este artigo tem como objetivo fazer uma reflexão acerca do pensamento do filósofo Jean-Jacques Rousseau (1712-1778) desde sua crítica ao direito divino e à degeneração dos costumes pelo estabelecimento das artes; seu pensamento político e a ideia desenvolvida na obra $O$ contrato social de uma sociedade justa, legítima e democrática regida pela vontade geral e por um povo soberano e livre; até seu projeto pedagógico de educação natural (negativa) e moral (positiva), exposto em Emílio ou da educação, onde buscou pensar como seria possível formar um povo soberano e estabelecer a vontade geral em uma sociedade corrompida através de uma educação que formasse indivíduos livres, independentes e morais.

PALAVRAS-CHAVE: Rousseau. Educação. Contrato Social. Soberania. Liberdade.

RESUMEN: Este artículo tiene como objetivo hacer una reflexión acerca del pensamiento del filósofo Jean-Jacques Rousseau (1712-1778) desde su crítica al derecho divino y a la degeneración de las costumbres por el establecimiento de las artes; su pensamiento político y la idea desarrollada em la obra El Contrato Social de una sociedad justa, legítima y democrática regida por la voluntad general y por un pueblo soberano y libre; hasta su proyecto pedagógico de educación natural (negativa) y moral (positiva), expuesto en Emilio o de la Educación, donde buscó pensar cómo sería posible formar um pueblo soberano y establecer la voluntad general en una sociedad corrupta mediante una educación que formase individuos libres, independientes y morales.

PALABRAS CLAVE: Rousseau. Educación. Contrato social. Soberanía. Libertad.

ABSTRACT: This article aims to reflect on the thinking of the philosopher Jean-Jacques Rousseau (1712-1778) from his critique of the divine law and the degeneration of customs by the establishment of the arts; his political thought and the idea developed in the workt The Social Contract of a just, legitimate and democratic society governed by the general will and by a sovereign and free people; until his pedagogical project of natural (negative) and moral (positive) education, exposed in Emilio or Education, where he tries to think how it would be possible to form a sovereign people adn to establish the general will in a corrupt society through an education that formed free, independent and moral individuals.

1 Faculdade de Educação da Universidade de São Paulo (Usp), São Paulo - SP - Brasil. Graduanda em Pedagogia. E-mail: sophia.breymaier@usp.br. 
KEYWORDS: Rousseau. Education. Social contract. Sovereignty. Freedom.

\section{Introdução}

O século XVIII foi marcado por grande fermentação e produção intelectual como também foi marcado por tensões entre o Antigo Regime absolutista e a burguesia emergente. Em meio de muitas contradições vemos na educação uma tendência ao liberalismo e à laicização buscando novos caminhos para a aprendizagem. Este século, conhecido não à toa como o Século das Luzes, foi guiado pelo poder da razão humana que vinha sendo anunciado desde o Renascimento quando, no humanismo, têm-se uma nova concepção do ser humano e valorização do indivíduo; uma visão antropocêntrica que resgata a dimensão humana em todos seus aspectos.

Há também uma tendência de secularização do saber, desde o Renascimento, que se fortifica no Iluminismo. O indivíduo quer não apenas conhecer por conhecer ou contemplar, quer conhecer para transformar, dominar a natureza, dessacralizando e desvinculando-a da religião; tornando o conhecimento laico e amplamente divulgado - como o faz os enciclopedistas, representados por Diderot e D'Alambert. Todos acreditavam nas luzes da razão e que o conhecimento emancipava. Assim o estabelecimento das ciências e das artes teria contribuindo para o aprimoramento dos costumes e aperfeiçoamento da humanidade, uma vez que o saber tornava o homem mais humano - formando um espírito culto, erudito, ou mais cortes. Rousseau, apesar de apresentar a inovação do pensamento iluminista em seu sentido político, como antiabsolutista, será contrário a essa concepção do conhecimento. Acreditava que o processo civilizador - as práticas de civilidade - eram enganosas e ofuscavam o que a pessoa tinha por dentro - suas disposições naturais-, contribuindo, portanto, para a deterioração dos costumes e da sociedade.

Ao invés de fazer um elogio ao conhecimento, como seu amigo Diderot, Rousseau vai dizer que a questão do sentido, das emoções e sentimentos é muito mais importante do que a racionalização e é também anterior a ela, negando o primado da racionalidade sobre a condição humana. "Não se começou raciocinando, mas sentindo" (ROUSSEAU, 1983b, p. 163). Por isso critica instituições e determinado modelo de sociedade que pautavam na razão todas as suas apostas, como o fazia os colégios e a educação de seu tempo.

O Iluminismo expandiu-se pela Europa com as publicações das Enciclopédias que reuniam verbetes de diversos pensadores da época como D'Alembert, Diderot, Rousseau, 
Helvétius e Voltaire. Estes por exemplo, não eram educadores no estrito sentido, mas pensavam a educação como instrumento das luzes da razão, embora divergissem entre si em vários outros aspectos. O século XVIII foi um período de intensas mudanças políticas, sociais e econômicas que vinham se pronunciando desde os primórdios da Idade Moderna, que é caracterizada até aqui pelas contradições e ambiguidades comuns a momentos de transição e transformação.

\section{Jean Jacques Rousseau}

Jean Jacques Rousseau nasceu em Genebra, Suíça, em 1712. Filho de relojoeiro, perdeu a mãe $\operatorname{logo}$ ao nascer. Vinha de família de médio escalão e passou por muitas dificuldades na sua infância, tanto financeiras como também afetivas. Rousseau é abandonado por seu pai que depois vem a falecer, fica aos cuidados de um tio, pastor protestante, e com 16 anos vai embora para Savóia. Por um tempo ganha a vida como professor de música e como preceptor de dois meninos da aristocracia em 1740, já tendo sido aprendiz de relojoeiro, pastor e gravador. Cansado da vida na cidade vai para o campo pra viver em contato com a natureza e elaborar seus projetos intelectuais.

De seu primeiro contato com educação escreveu tempos depois Projetos para a educação do Senhor de Sainte-Marie, uma crítica aos parâmetros rígidos dos colégios e educação de seu tempo, assim como também relata sua experiência pedagógica como preceptor, desenvolvendo planos de educação para crianças reais que mantivesse harmoniosa a educação recebida pelo pai e pelo preceptor através de um contrato. Diferente de Emílio ou da educação onde Rousseau inventa uma criança. Defendia uma educação integral, com níveis proporcionais à idade de ensino, espaço próprio para o aprendizado e tempo ideal - que seria pelas manhãs - e além disso, se opunha a castigos físicos.

Em 1742, muda-se para Paris onde conhece filósofos como Diderot e D'Alembert e os enciclopedistas, amadurecendo suas concepções políticas e filosóficas. Em 1749 publicou o Discurso sobre as ciências e as artes, premiado com medalha de ouro pela Academia de Dijon, e em 1755, o Discurso sobre a origem e os fundamentos da desigualdade entre os homens onde aparecem as bases do processo gerador das desigualdades sociais e morais entre os homens e dá início à discussão do contrato social, aproximando duas visões de mundo - a do homem no estado natural e a do homem no estado civil. Na obra O Contrato Social procura o fundamento da autoridade legítima com o objetivo de "instituir os princípios dos direitos políticos entre homens" (DALBOSCO, 2011, p. 27) e idealizando uma sociedade 
justa e democrática regida pela vontade geral. Pra isso, ele vai tentar construir um Estado que é concebido como um ente de razão, um ente moral, pois pensava que para que essa ordem social fosse possível a estrutura político-jurídica deveria se fundar a na capacidade moral de cada cidadão de governar-se e submeter-se às leis. E tal moralidade nas ações e o governo de si mesmo serão por sua vez, fruto de uma educação específica pensada também por Rousseau, na qual deposita grande importância e está interligado com seu projeto político.

Jean J. Rousseau era crítico dos governos absolutistas fazendo parte da escola que critica o direito divino - a escola do direito natural de Hobbes, Locke e Rousseau. Nesse caso ele conflui com o pensamento iluminista indo de frente com autores que defendem a causa religiosa como legitimação para o poder político de alguns, teoria que tende a defender uma submissão absoluta dos súditos em relação ao governante, implicando na proibição da resistência do povo. No entanto, quando Rousseau apresenta crítica ao progresso científico em seu Discurso sobre as ciências e as artes responsabilizando-o pela degradação moral do homem, vai à contramão do pensamento iluminista que percorria o imaginário da maioria.

Ele vai contra os fatos dados, as evidências - palavras que têm raiz na teoria fisiocrática, na qual a evidência é algo tão claro por si mesma que não há como negá-la. Ele rompe com essa concepção que naturalizava uma ordem social motivada historicamente, dizendo que é preciso separar os fatos do que é por direito; tentando estabelecer os princípios do direito usando como recurso a razão e a abstração. Assim ele consegue julgar a realidade na qual vive com base na razão, e a partir da abstração pensar um ideal de mundo, um modelo de sociedade e de educação que permita que as evidências de fato coincidam com o direito. Construindo outra sociedade pensando a liberdade fundamentada no direito natural, em oposição à sociedade em que vive, fundada sob um pacto social ilegítimo e imoral.

\section{Concepção política}

"O verdadeiro fundador da sociedade civil foi o primeiro que, tendo cercado um terreno, lembrou-se de dizer isto é meu e encontrou pessoas suficientemente simples para acreditá-lo.” (ROUSSEAU, 1983a, p.259) Para Rousseau a propriedade foi um acaso que produziu a sociedade civil e que o pacto que a institui deve ser substituído por outro. Ele propõe uma nova sociedade que mantenha a propriedade como fruto do trabalho e não da herança. E o que irá assegurar a nova sociedade é uma ideia de soberania e de vontade geral, além de um contrato social entre todos. 
Em "Emílio ou da educação" e em "O contrato social”, Rousseau pensa numa base antropológico-filosófica que concebe o homem natural e o homem social, no estado de natureza e no estado civil, respectivamente. No estado de natureza todos seriam iguais e viveriam independentes e livres. As preocupações que o homem teria seriam consigo mesmo. Não haveria razão, raciocínio e sim sentido, sentimentos. O sentimento característico do homem natural seria o amor-de-si, diretamente relacionado com as necessidades naturais (de auto conservação) sendo uma preferência por si próprio. Ele é uma bondade natural e, dessa forma, não possui caráter moral. É este sentimento que orienta a vontade do homem natural. O sentimento do homem social seria o amor-próprio, e Dalbosco (2011) aponta que, entre estes sentimentos se intercalaria a piedade (o reconhecimento de si no outro), e que ela é afetada pela transformação do amor-de-si em amor-próprio, tornando-se mais intenso e abrindo caminho para sentimentos "maldosos e odientos das paixões humanas, canalizadas, racionalmente, pelo amor-próprio" (DALBOSCO, 2011, p. 38) como a vergonha, inveja, desprezo, entre outros.

O amor-próprio que rege o homem social está ligado às necessidades artificiais e a uma busca de superação à custa dos outros, o que torna a condição do homem no estado civil corrupta e perversa. É um amor egoísta com tendência de controlar e dominar os outros para satisfazer suas necessidades particulares. Este sentimento, sim, tem caráter moral, diferente do amor-de-si. A passagem do estado natural para o social é, logo, concebida no pensamento de Rousseau como a transformação da bondade natural (amor-de-si) em egoísmo racional (amorpróprio) através de um pacto em defesa da sociedade e da propriedade. Para Rousseau, veremos que este pacto é falso e que a propriedade privada é um roubo, e não um direito natural. Irá propor então um novo pacto, legítimo, onde todos são soberanos - o Contrato Social.

\section{Legitimidade: crítica ao pacto de submissão}

Para Rousseau (1996), só há escravos por natureza porque houve escravos contra a natureza. Inicia sua discussão sobre legitimidade de poder refutando teorias que assemelhavam o pacto social a um pacto de submissão. Começa por negar a analogia família/Estado, na qual a imagem do chefe estaria ligada à do pai, e a do povo à do filho. Isso se dá, em primeiro lugar, a relação pai e filho não é de equidade sendo o filho submetido aos cuidados do pai, ou seja, o filho aliena sua liberdade por necessidade de conservação. Em segundo lugar, na teoria política rousseauniana, o Estado legítimo seria fruto de convenções, 
ou seja, seria fruto de um pacto social feito entre iguais e obedeceria à vontade geral que emanaria do povo, o soberano legítimo, tendo em vista, então, a um bem comum, e não poderia jamais agir de forma patrimonialista -como na sociedade da família- ou segundo interesses particulares, pois estaria assim rompendo com uma das cláusulas deste pacto.

Rousseau (1996) também nega a ideia da força como base do direito, uma vez que sendo a força um poder físico, ceder a ela passa a ser uma necessidade e não um ato de vontade, não sendo um dever e não podendo, portanto, ser fundamento do direito. Dessa forma também em seu projeto de educação natural e moral em Emílio ou da educação se afirma contra castigos físicos e punições para estabelecer a ordem e obediência. Faz uma crítica aqui ao direito do mais forte de Hobbes e à transformação da força em obediência e direito como sendo um equívoco por tomar o efeito pela causa, pois só se é obrigado a obedecer aos poderes legítimos, e como homem algum tem autoridade natural sobre outro, a base da autoridade legítima entre os homens está nas convenções.

Nenhum homem tem direito de comprar o outro ou de se vender, a liberdade para Rousseau é inalienável. Ele é, portanto, contra a escravidão, pois tem uma preocupação moral de manter a dignidade do homem, que é perdida junto com sua liberdade. Alienar sua liberdade seria renunciar à condição do homem, aos direitos da humanidade e deveres. "Faço contigo uma convenção em que fica tudo a teu encargo e tudo em meu proveito, que observarei enquanto me aprouver, e que tu observarás enquanto isso me agradar."(ROUSSEAU, 1996, p. 18). O direito de escravizar é uma convenção sem sentido aos olhos de Rousseau, e também ilegítima.

O pacto social é de união e não de submissão e seria anterior ao pacto de escravidão como fundamento da sociedade civil, pois para haver um pacto de submissão é necessária a prévia formação de um povo e constituição de uma pessoa moral, entrando aqui a necessidade de uma educação capaz de formar indivíduos livres e independentes capazes de governarem a si mesmos. E como sabemos, de acordo com Rousseau (1996), o povo se constitui como povo através do pacto social. Ele rejeita a ideia do pacto de submissão, entre outros motivos, pois ela é incompatível com a ideia de soberania, que se origina, se localiza e está sempre sendo regulamentada pelo povo.

\section{Contrato Social: alienação dos direitos naturais como troca vantajosa}

Quando os homens, no estado natural, chegam a um ponto em que suas forças não bastam para se conservarem e é preciso, então, formar um conjunto de forças que haja em 
comum acordo, Rousseau se depara com um problema fundamental para sua busca da legitimidade da autoridade:

Encontrar uma forma de associação que defenda e proteja com toda a força comum a pessoa e os bens de cada associado, e pela qual cada um, unindo-se a todos, só obedeça, contudo, a si mesmo e permaneça tão livre quanto antes. (ROUSSEAU, 1996, p. 20-21).

E a resposta a esse problema será um pacto social, que é para ele legítimo e verdadeiro, pelo qual o povo se reúne sob uma mesma vontade, a vontade geral, criando um corpo político que é um ser moral coletivo e garantindo igualdade jurídica e moral.

Para ser legítimo esse pacto social se resume a uma só cláusula fundamental, "a alienação total de cada associado, com todos os seus direito, a toda a comunidade" (ROUSSEAU, 1996, p. 21), pois se aos particulares sobrassem alguns direitos naturais, estes poderiam deles usufruir para realizar seus interesses pessoais, a vontade geral tenderia a uma vontade particular e o pacto seria desfeito. Essa alienação é consciente e voluntária, diferente da alienação dos direitos e bens submetida à lei dos mais fortes, que é um caso de necessidade. Ela também difere da ideia de supressão dos direitos naturais do indivíduo, devido à condição inalienável da liberdade que Rousseau defende e, também, pois o que ocorre com o estabelecimento do pacto social é a conversão dos direitos naturais em direitos civis. Cada associado ao contrato troca sua liberdade natural pela liberdade civil, e passando então para o estado civil, encontra-se tão livre quanto antes, uma vez que o pacto garante a sua liberdade, ou seja, garante sua independência e a igualdade. Para Rousseau (1996), a liberdade é a igualdade e, portanto, só se é livre quando ninguém é tão rico ou tão pobre a ponto de haver dependência entre os indivíduos. "Cada um dando-se a todos não se dá a ninguém" (ROUSSEAU, 1996, p. 21), assim, a alienação total dos direitos naturais mantém a igualdade na medida em que ela é total para todos os associados e só é legítima porque se faz em benefício de todos.

A alienação total é, pois, uma forma de garantir que o indivíduo viva sem dependência pessoal, e em troca da alienação de seus direitos naturais, freando seus desejos de interesse pessoal através do desenvolvimento de suas forças e à posse de tudo que puder alcançar, receberá benefícios oferecidos por um governo legítimo e justo, e essa troca é caracterizada por Rousseau (1996) como uma 'troca vantajosa', pois aquilo que se perdera do estado natural pelo pacto, tem-se agora em forma de liberdade civil e moral, ou seja, substituise na conduta do indivíduo o instinto e a preferência por si mesmo (amor-de-si) pela justiça e a piedade, tomando moralidade em suas ações, desenvolvendo suas capacidades e ideias, 
enobrecendo os sentimentos perversos do amor-próprio em direção à perfectibilidade tornando-se senhor de si mesmo. Então, apesar de perder-se algumas vantagens, no estado civil "ganha-se o equivalente de tudo o que se perde e mais força para conservar o que se tem"(ROUSSEAU, 1996, p. 21).

[...] a passagem da liberdade natural para a liberdade político-jurídica, assentando-se na firme convicção(moral) de que uma ordem social justa, baseada em princípios democráticos amparados juridicamente, só é possível de ser realmente viabilizada quando a capacidade humana de se dar a si mesmas a lei (ideia de auto legislação) se tornar norma de conduta de todo cidadão republicano. (DALBOSCO, 2011, p. 27).

Ao fazer esse pacto, Rousseau (1996) também diz que além de haver trocas vantajosas não há de fato uma renúncia por parte dos indivíduos contratantes. Isso se dá tanto pelo fato já mencionado de que há na verdade uma conversão dos direitos e bens naturais em direitos e bens civis (propriedade) como também pelo fato do contrato estabelecer uma igualdade entre os associados, que se submetem às mesmas condições e usufruem dos mesmos direitos ao constituírem um pacto onde todos contratam com todos. E por isso, todo ato de soberania, o qual provém da vontade geral (expressa na lei) e, portanto, do povo, 'obriga e favorece' de forma igual a todos, sem haver distinções por parte do poder soberano daqueles que fazem parte do corpo político.

\section{Vontade Geral e Soberania}

O estabelecimento do pacto social possibilita ao indivíduo a passagem do estado natural, por meio da alienação total dos direitos e bens naturais, ao estado social onde a liberdade natural é convertida em liberdade moral (político-jurídica), que é por sua vez limitada pela vontade geral, e não mais pela força física do indivíduo. É por meio do pacto, também, que há a constituição do corpo coletivo, o povo, e de um corpo político, um 'ser artificial' e moral (Estado, soberano) e que age de acordo com a vontade geral.

A vontade geral é a vontade do povo, mas também a vontade de cada associado ao pacto enquanto membros da comunidade ou do soberano e não enquanto indivíduos particulares, não sendo, portanto, uma soma das vontades particulares, as quais visam um interesse particular e não o bem-comum, que é o bem visado pela vontade geral. A vontade geral só existe, de acordo com Rousseau (1996), quando todos querem a felicidade de cada um deles, daí decorre o interesse da vontade como sendo um interesse geral, não distinto, porém, do interesse do indivíduo, pois é seu próprio interesse que o cidadão visa ao submeter- 
se à vontade geral, e esta como sendo uma 'regra de justiça' é aceita por ele para garantir sua própria segurança e liberdade, ou seja, contra a dependência pessoal e a injustiça.

Assim, o pacto social consiste no contrato do povo consigo mesmo que é súdito e também soberano. A soberania inalienável (pois é o exercício da vontade geral) e que é legítima, portanto, origina-se, localiza-se e está sendo constantemente regulamentada pelo povo e não há outro soberano legítimo. A soberania é assim orientada pela vontade do povo e executada nas leis, expressão racional da vontade geral que garantem o cumprimento desta.

O povo soberano, sendo ao mesmo tempo parte ativa e passiva, ou seja, fazendo parte do processo de elaboração das leis e obedecendo a elas estaria de tal forma submetendose a si mesmo, sendo senhor de si mesmo e, portanto, independente de qualquer outro indivíduo, pois as leis nada mais são do que a expressão das próprias vontades do indivíduo e de qualquer um que seja associado ao pacto. Para Rousseau (1996) a obediência às leis que nos impomos é a própria liberdade. A seus olhos, o povo poderá ser livre apenas quando tiver as condições necessárias para criar suas leis de forma justa e igual, de maneira que a obediência a elas seja um ato de liberdade e soberano, ou seja, de submeter-se ao governo de si mesmo e de cada um dos outros indivíduos que formam o povo; isto é, submeter-se à vontade geral e não à vontade de um ou grupos de indivíduos.

Assim, a vontade geral que surge da passagem do estado natural para o estado civil, que visa o bem comum - tendo assim como objeto não o particular, o indivíduo, e sim o geral - é conceito que permeia toda a obra de Rousseau, em $O$ Contrato Social, e é fundamental para se entender como se dá a legitimidade da autoridade no estado civil através da combinação perfeita entre liberdade e obediência.

\section{A pedagogia de Rousseau}

O cidadão, ativo e soberano, capaz de autonomia e liberdade, é ao mesmo tempo um súdito, porque se submete à lei que ele próprio ajudou a erigir. Liberdade e obediência são pólos que se devem completar na vida da pessoa em sociedade. Por aí já devemos antever a importância que Rousseau deposita na educação. (ARANHA, 2006, p. 117).

Jean-Jacques Rousseau escreve a obra Emílio ou da educação em 1772, no mesmo ano em que publicou $O$ contrato social, e a considera como sua obra mais importantes onde elabora um projeto de educação natural e social (moral) que busca estabelecer as características de um homem soberano capaz de se tornar cidadão republicano. Como coloca 
Aranha (2006), o pensamento pedagógico de Rousseau não se separa de sua concepção política. Para Rousseau (1996) o homem nasce livre e por toda parte ele está amarrado, o indivíduo em estado de natureza é bom, mas a sociedade o corrompe e destrói sua liberdade.

Ele inverte a centralização dos interesses pedagógicos do professor para o aluno ressaltando uma especificidade da infância, tendo a criança maneiras próprias de ver, de sentir e de pensar. Por isso há a necessidade de tratá-las como crianças e não como adultos em miniaturas, pois "a natureza quer que as crianças sejam crianças antes de ser homens" (ROUSSEAU, 1995, p. 75) e perturbar essa ordem impondo a razão antes do tempo adequado pode produzir 'frutos precoces' suscetíveis a corromperem-se. Rousseau (1995) assinala ainda que a razão é o freio da força e a criança não tem necessidade desse freio; é preciso tratar o aluno segundo sua idade e de acordo com suas condições.

Os fins da educação proposta por Rousseau também vão diferir das concepções vigentes de formação para os costumes e para a civilidade, ou seja, para a vida em sociedade ou para Deus nos colégios e escolas de caridade de sua época. Ele pensa uma formação integral, do corpo e do espírito, para se aprender a viver, e que a primeira coisa que a criança deve aprender e tem necessidade de saber é sofrer. O fim de sua educação é formar homens livres e autônomos - obedientes a si mesmos, que é a própria liberdade - através de uma educação 'conforme a natureza', conforme a vocação humana, para que possa ser depois inserido na sociedade corrompida sem corromper-se e através de uma educação moral.

\section{A educação natural e a educação moral}

Rousseau (1995) critica a educação de seu tempo, rígida, intelectualista, voltada para o ensino formal e livresco e que não respeita a criança como tal; que a constrange e corrompelhe o espírito colocando-a em contato com os vícios e a hipocrisia da sociedade; que por uma mania arrogante de educar ensina às crianças o que aprenderiam melhor sozinhas; que lhe tira a liberdade pensando em educá-la para um futuro que pode nunca chegar; e que concebe a criança com uma natureza má que deve ser adestrada. Por isso, propõe uma educação primeira que não é apenas naturalista - é também negativa - e depois uma educação social (moral) positiva - e onde a segunda só se realiza se a primeira tiver sido efetiva.

Compara a infância com o estado de natureza, as crianças teriam os mesmos sentidos, emoções e instintos que os homens no estado de natureza e, portanto, tinha uma razão anterior à razão lógica, que é uma razão sensitiva. Valorizava a experiência, a educação ativa e para o ofício de viver. A educação negativa consiste em deixar a natureza agir, preservando o 
coração puro da criança, porém afastando-a dos vícios da sociedade. Por isso pensa a educação de Emílio no campo e prolonga a infância até os doze anos, ao invés de sete anos. Abarcando tanto a primeira como a segunda infância, a educação negativa dá ênfase ao processo do "fortalecimento do corpo e refinamento dos sentidos" devendo ser "orientada pelo convívio do educando com as coisas" (DALBOSCO, 2011, p. 32) e habituando a criança a relacionar-se com a natureza e seu governante - o preceptor. Sem dar muito valor ao conhecimento transmitido e a uma racionalidade imposta de fora para dentro, Rousseau acreditava que a criança aprenderia a pensar por um desenvolvimento interno e natural.

No entanto, o preceptor não deve deixar a criança no espontaneísmo, pois para se tornar um adulto autônomo precisa aprender a lidar com seus desejos e conhecer os limites de suas forças, e assim poder ter liberdade, pois a liberdade é obediência à lei que ele mesmo criou, é a capacidade de governar-se.

Que ele saiba apenas que é fraco e que sois forte; (...) que ele o saiba, que o aprende, que o sinta; que sinta desde cedo sobre sua cabeça altiva o jugo que a natureza impõe ao homem, o pesado jugo da necessidade, ao qual deve dobrar-se todo ser feito; que veja essa necessidade nas coisas, nunca no capricho dos homens; que o freio que o segure seja a força e não a autoridade. (ROUSSEAU, 1995, p. 76-77).

Da mesma forma como no processo de cidadania em que o indivíduo se submete à vontade geral, como diz Aranha (2006) “também a criança descobrirá por si própria as leis das coisas e das relações pessoais". Além disso, para ser um bom educador o preceptor deve conhecer e respeitar as leis naturais e a especificidade da infância, seu aluno, para que tal conhecimento o conduza a intervenções pedagógicas que sejam adequadas e não corrompa seu espírito.

A miséria, segundo Rousseau (1995) consiste na desproporção entre nossos desejos e nossas faculdades ou capacidades - da necessidade que sentimos das coisas -, assim, para ser absolutamente feliz tem-se que igualar os desejos e as faculdades. A sabedoria humana consiste então, em equilibrar perfeitamente à vontade e o poder. $\mathrm{O}$ mundo real, a sociedade corrompida pelo pacto de submissão, aumentam nossos desejos e também limitam nossas capacidades trazendo miséria ao homem. Dessa forma a educação que ele propõe, é justamente uma formação para que a criança se torne um "homem realmente livre que só quer o que pode e faz o que lhe apraz. Eis minha máxima fundamental.” (ROUSSEAU, 1995, p. $67)$. 
A segunda etapa do processo educativo, Rousseau (1995) a nomeia educação social (moral) ou positiva. É uma etapa de intensa sociabilidade, quando se deve aprender com os outros a conviver de forma soberana e ela só pode ser realizada se a educação natural tiver sido adequada. É o ingresso de Emílio na vida social, onde se deve exercitar o "emprego adequado da razão, na determinação racional da vontade e, portanto, no domínio moral de si mesmo" (ROUSSEAU, 1996, p.21) que é essencial para bem governar a si mesmo e aos outros. Assim começa a vida do indivíduo quando a criança toma consciência de si mesma e o desenvolvimento de suas forças permite o governo de si, devendo agora ser considerada um ser moral. A educação moral pretende tornar possível a passagem de um estado de dependência para independência, e consiste em ensinar o aluno a ouvir sua consciência que é, como assinala Dalbosco (2011) a capacidade de julgar que reside na razão e da sensibilidade que brota do coração.

É pela educação que o homem é capaz de abandonar sua selvageria (menoridade) e conquistar sua independência (maioridade), porque é por meio dela que vem a ser capaz de criar uma fortaleza interior para poder exercer o domínio moral de si mesmo, domínio este indispensável para o exercício de um bom governo sobre os outros. (DALBOSCO, 2011, p. 28).

\section{Considerações finais}

Em relação à educação das mulheres, apesar de autores antes mesmo de Rousseau já pensassem uma maior participação das mulheres na sociedade - como Comênio que preconizava um método universal de ensinar tudo a todos e Condorcet que defendia o direito de cidadania das mulheres, como o direito ao voto -, ele considerava que as mulheres deviam ser educadas para servir aos homens dedicando-se às tarefas do lar. Em Emílio ou da educação chega a escrever sobre a educação de uma menina, Sofia, que deveria ser educada de 'acordo com seu sexo' para ser companheira de Emílio. Para ele havia uma diferença natural entre os sexos e por isso deveria ter educações distintas.

Foi acusado também de propor uma educação elitista em Emílio ou da Educação, por pensar um preceptor. Mas é importante lembrar que Rousseau está propondo, através de um método de abstração, uma relação ideal e hipotética, assim como em O Contrato Social, para pensar como seria possível uma educação natural em uma sociedade corrompida e, portanto, estabelecer a vontade geral e a soberania do povo em uma sociedade que ainda não é democrática através de uma educação moral e a formação de um indivíduo livre e autônomo. 
Como a formação moral do indivíduo só poderia acontecer com sua socialização, que acontece na medida em que o amor-próprio gradativamente se estabelece, a função pedagógica é a de transformar o egoísmo do amor-próprio em respeito pelos outros, recuperando assim, como afirma Dalbosco (2011) o aspecto piedoso do amor-de-si através, sobretudo, da relação pedagógica entre educador e educando.

O pensamento de Rousseau teve grande influência nos ideais da Revolução Francesa pautados na liberdade como valor supremo do homem, bem como várias correntes pedagógicas do século XX, como as tendências não diretivas. Rousseau faleceu em Ermenonville, França em 1778.

Homens, sejais humanos, é vosso primeiro dever; e o sejais em relação a todas as situações sociais, a todas as idades, a tudo o que não seja estranho ao homem. Que sabedoria haverá para vós fora da humanidade? Amai a infância; favorecei seus jogos, seus prazeres, seu amável instinto. (ROUSSEAU, 1995, p. 61).

\section{REFERÊNCIAS}

ROUSSEAU, Jean-Jacques. Emílio ou da educação. 3ed. Rio de Janeiro: Bertrand Brasil, 1995.

ROUSSEAU, Jean-Jacques. Discurso sobre a origem e o fundamento da desigualdade entre os homens. In: Os pensadores/Rousseau. 3.ed. São Paulo: Victor Civita, 1983a. p. 233-282.

ROUSSEAU, Jean-Jacques. Discurso sobre a origem das línguas. In: Os pensadores/ Rousseau. 3.ed. São Paulo: Victor Civita, 1983b. p.157-199.

ROUSSEAU, Jean-Jacques. Discurso sobre as ciências e as artes. In: Os pensadores/ Rousseau. 3.ed. São Paulo: Victor Civita, 1983c. p.321-352.

ROUSSEAU, Jean-Jacques. Projeto para a educação do Senhor de Sainte-Marie. Porto Alegre: Editora Paraula, 1994.

ROUSSEAU, Jean Jacques. O Contrato Social: princípios do direito político. 3.ed. São Paulo: Martins Fontes, 1996.

ARANHA, Maria Lúcia de Arruda. A História da Educação e da Pedagogia: geral e do Brasil. 3.ed. São Paulo: Moderna, 2006.

DALBOSCO, Claudio Almir. Da educação natural e da educação social (moral) no Emílio de Rousseau. In: Filosofia e educação no Emílio de Rousseau: papel do educador como governante. Campinas: Alínea, 2011. 


\section{Como referenciar este artigo}

BREYMAIER, Sophia Calil. Sociedade e Educação em Rousseau: do pensamento político ao projeto de educação natural e moral. Rev. Sem Aspas, Araraquara, v. 6, n. 2, p. 161-174, jul./ dez., 2017. E-ISSN: 2358-4238.

Submetido em: 01/12/2017

Aprovado em: 03/01/2018 